\title{
Wave Forces on a Large Structure in the Presence of a Current
}

\author{
Sung-Shan Hsiao \\ Associate Professor, Department of Harbor \& River Engineering, National Taiwan Ocean University, 2 Pei-Ning Rd. \\ Keelung, Taiwan. \\ Ming-Chung Lin \\ Professor, Department of Naval Architecture \& Ocean Engineering, National Taiwan University, 73 Chow-Shan Rd. \\ Taipei, Taiwan.
}

Follow this and additional works at: https://jmstt.ntou.edu.tw/journal

Part of the Civil and Environmental Engineering Commons

\section{Recommended Citation}

Hsiao, Sung-Shan and Lin, Ming-Chung (2009) "Wave Forces on a Large Structure in the Presence of a Current," Journal of Marine Science and Technology. Vol. 7: Iss. 1, Article 3.

DOI: $10.51400 / 2709-6998.2508$

Available at: https://jmstt.ntou.edu.tw/journal/vol7/iss1/3

This Research Article is brought to you for free and open access by Journal of Marine Science and Technology. It has been accepted for inclusion in Journal of Marine Science and Technology by an authorized editor of Journal of Marine Science and Technology. 


\title{
WAVE FORCES ON A LARGE STRUCTURE IN THE PRESENCE OF A CURRENT
}

\author{
Sung-Shan Hsiao* and Ming-Chung Lin**
}

Keywords: Wave forces, Large Structure, Wave-current Coexisting Field.

\section{ABSTRACT}

The wave forces acting on a large structure in the presence of a current have been investigated numerically. It is noted that the velocity potential in a wave-current coexisting field can be separated into an unsteady wave potential and a steady current potential. The unsteady wave potential with effects of both a uniform current and a large structure was calculated by using boundary element method. The steady current potential can be expressed as the sum of a uniform current and a steady disturbance due to the existence of the structure. This means that current velocity will be changed in the vicinity of the structure. The variation of current velocity around the structure was then calculated by using a surface vorticity method. Substituting both unsteady wave potential and current velocity distribution into the first-order dynamic pressure equation and integrating the pressure over the body surface, the first-order wave forces on a large structure in the presence of a current then can be obtained. Comparison of the present results with those of Matsui et al. (1991) are made. The agreement is satisfactory. The numerical model proposed here has its adaptability to the problem of waves, current and a large structure interactions.

\section{INTRODUCTION}

When waves propagate toward a large structure, the existence of currents in ocean having different characteristics complicates the problem concerning the interactions between wave and current around the structure. With increasing engineering activities in both coastal and offshore regions nowadays, accurate predictions of wave forces and, thereby the responses of large structures, in the presence of currents have become progressively important.

To study the interactions between current, wave

Paper Received Jan. 29, 1999. Accepted Mar. 24, 1999. Author for Correspondence: Sung-Shan Hsiao.

*Associate Professor, Department of Harbor \& River Engineering, National Taiwan Ocean University, 2 Pei-Ning Rd. Keelung, Taiwan.

**Professor, Department of Naval Architecture \& Ocean Engineering, National Taiwan University, 73 Chow-Shan Rd. Taipei, Taiwan. and slender cylinders, Iwagaki and Asano (1984) performed flow visualization tests to examine the vortex property around a circular cylinder in a wave-adverse current coexisting field. The hydrodynamic forces acting on the cylinder are also discussed by them. Based on the linear wave theory, Li and Zhang (1990) investigated forces on cylinders under the actions of both regular waves and currents. A series model tests of regular and irregular wave-current forces on slender circular cylinders were carried out by Li et al. (1991).

To investigate the interactions of wave-current around a large structure, Zhao and Faltinsen (1988) developed a theory to the first-order in wave amplitude and current velocity. An algorithm to solve the interaction between waves and currents with a two-dimensional body was also presented by them. Lin and Hsu (1991) proposed a numerical scheme to study the interactions of wave-current around a large structure. The numerical scheme is based on the mild-slope wave equation derived by Kirby (1984), where the effects of wave refraction-diffraction, together with currents, on a slowly varying topography were considered. To verify the validity of their numerical scheme, model tests in a laboratory basin were also conducted by Lin et al. (1990). The hydrodynamic forces on a vertical cylinder in current and waves were also analyzed by Matsui et al. (1991). The significant influence on hydrodynamic forces of the cylinder due to the presence of a current is reported. You and Tao (1992) investigated the nonlinear wave-current forces on large scale cylinders by time-stepping method. Isaacson and Cheung (1993) presented a time-domain solution for wave-current interactions with a two-dimensional body. A numerical model using finite/boundary element method was proposed by Lin et al. (1994) to deal with wave refraction-diffraction in the presence of a current. Lin and Hsiao (1994) proposed a numerical approach for wave-current interaction around a large structure. The distribution of wave height around a large cylinder in a wave-current coexisting field was calculated and compared with experimental results. Wave height variations around a large cylinder due to wave-current 
interactions were studied experimentally by Lin and Hsiao (1995). Both the cases of slowly varying topography, as well as with constant water depth, were considered.

The general approach for the velocity potential of a wave-current coexisting field is to separate the velocity potential into a steady current potential and an unsteady wave potential. The steady current potential can be expressed as the sum of a uniform current and a steady disturbance which resulted through the presence of the structure in the flow field. This then leads to alteration of the current velocity in the vicinity of the structure. For a structure of arbitrary shape, it is difficult to find a closed form solution but a numerical solution may be obtained by a direct application of an integral equation method (Isaacson and Cheung, 1993). In this paper, the surface vorticity method due to Lewis (1991) was used to obtain the needed boundary integral equation. The variation of the current velocity due to the existence of the structure was then directly found by solving this equation numerically. Boundary element method was used to calculate the unsteady wave potential which resulted from the presence of a uniform current and the structure. Assuming that the wave is

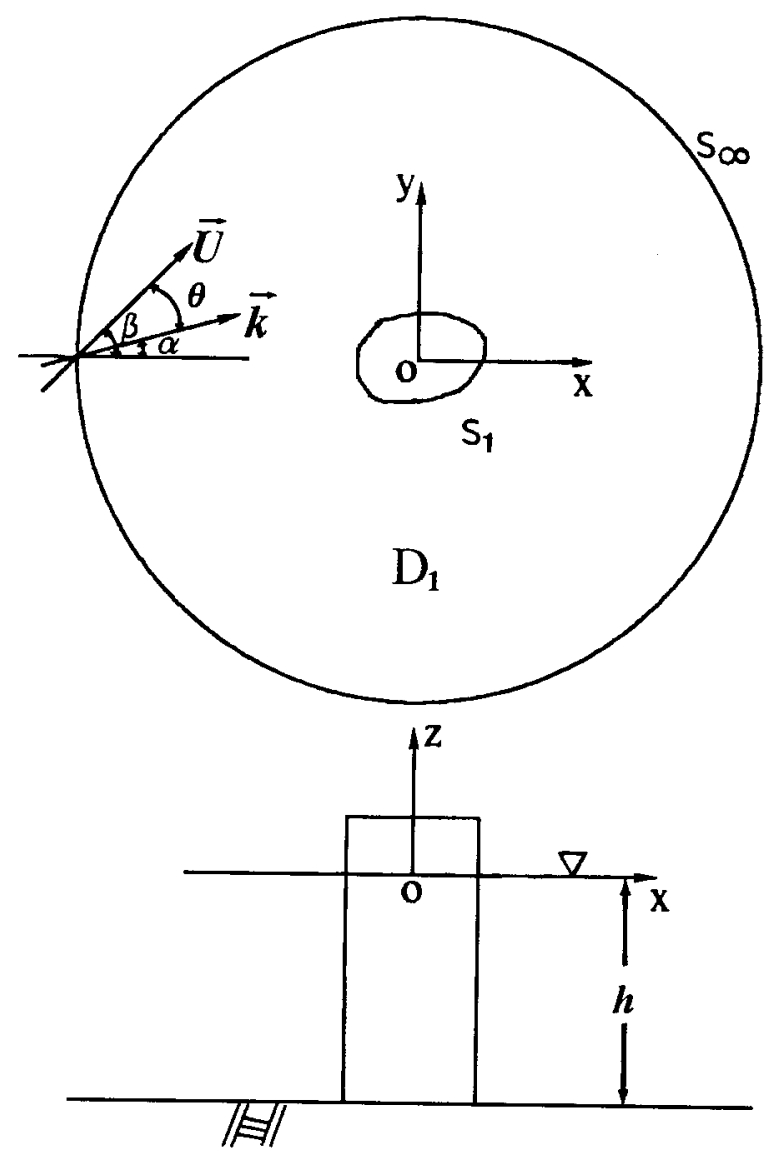

Fig. 1. Definition sketch of the computational domain. small amplitude motion and the current velocity is rather small, one can obtain a first-order dynamic pressure equation. Substituting both the unsteady wave potential and the current velocity into the equation and integrating the pressure over the structure surface, the first-order wave forces on a large structure in the presence of a current were obtained.

\section{THEORETICAL FORMULATION}

The problem of wave forces acting on a large structure under the effect of a current is considered. With reference to figure 1 , the problem is defined with a fixed coordinate system $o-x y z$, in which $x y$-plane is on the still water level, $o$ is at the center of the body, and $z$ is measured vertically upwards from the $x y$-plane. The seabed is assumed to be impermeable and horizontal along the plane $z=-h$. $U$ is the current velocity and is assumed to be uniform with depth, $k$ is the wave number of incident waves. $\alpha$ and $\beta$ are, respectively, the inclinations of wave and current to the $x$ axis, $\theta=\beta$ - $\alpha$ is then the angle between waves and current.

\section{Velocity potential}

Assuming fluid in the wave-current coexisting field is incompressible and inviscid, and the flow irrotational, the fluid motion can then be described by a velocity potential $\Phi$ which satisfies the Laplace equation:

$$
\nabla^{2} \Phi=0
$$

The potential $\Phi$ is also subjected to boundary conditions on the seabed, the structure surface, and the free surface, which are given, respectively, as

$$
\begin{aligned}
& \frac{\partial \Phi}{\partial z}=0, \quad z=-h \\
& \frac{\partial \Phi}{\partial n}=0, \text { on } S_{1} \\
& \frac{\partial \Phi}{\partial t}+\frac{1}{2}(\nabla \Phi \cdot \nabla \Phi)+g z=c, \quad z=\eta
\end{aligned}
$$

Here, $\frac{\partial}{\partial n}$ is the derivative, normal to $S_{1}$, the surface of the structure; $t$ denotes time and $g$ is the gravitational constant; $\eta$ and $\mathrm{c}$ are, respectively, the water surface elevation above the still water level and the Bernoulli's constant.

The potential $\Phi$ can be separated into a steady current potential and an unsteady wave potential, as

$$
\Phi=\phi_{u}+\phi_{w}
$$

The current velocity in the vicinity of the structure will be altered due to the presence of the object. Thus, 
the steady current potential $\phi_{u}$ can be expressed more conveniently as the sum of a uniform current potential $\vec{U} \cdot \vec{x}$ and a steady disturbance potential $\phi_{b}$ caused by the structure in the flow (Isaacson and Cheung,1993).

$$
\phi_{u}=\vec{U} \cdot \vec{x}+\phi_{b}
$$

The unsteady wave potential $\phi_{w}$ in a wave-current coexisting field is given by linear wave theory, as

$$
\phi_{w}=-\frac{i g A}{\sigma} \frac{\cosh k(z+h)}{\cosh k h} f e^{-i \omega t}
$$

where $A$ is amplitude of the incident wave, $i$ is the imaginary constant, and $g$ is the gravitational constant, $\omega$ and $\sigma$, denote, respectively, the absolute and relative angular frequency in the wave-current coexisting field. The wave number $k$ and the angular frequency $\omega, \sigma$ are related by the linear dispersion and Doppler relation such as

$$
\begin{aligned}
& (\omega-\vec{k} \cdot \vec{U})^{2}=g k \tanh k h \\
& \sigma=\omega-\vec{k} \cdot \vec{U}
\end{aligned}
$$

In equation (7), $f$ denotes the surface potential function. It is noted that, using the diffraction theory approach, $f$ can be expressed as a linear combination of surface potential functions resulting from both incident and scattered waves:

$$
f=f^{i}+f^{s}
$$

where $f^{i}$ is surface potential function of the incident wave, and can be expressed as

$$
f^{i}=\exp [i k(x \cos \alpha+y \sin \alpha)]
$$

Substituting equations (5), (6), (7), (10) and (11) into equation (1), and applying boundary conditions on the surface of the structure, as well as a far-field radiation boundary condition, the surface potential function of the scattered wave $f^{s}$ in the analytical domain satisfying Helmholtz equation is given by:

$$
\begin{aligned}
& \nabla_{h}^{2} f^{s}+k^{2} f^{s}=0, \quad \nabla_{h}=(\partial / \partial x, \partial / \partial y) \\
& \frac{\partial f^{s}}{\partial n}=-\frac{\partial f^{i}}{\partial n}, \quad \text { on } S_{1} \\
& \lim _{r \rightarrow \infty} \sqrt{r}\left(\frac{\partial}{\partial r}-i k\right) f^{s}=0, \text { on } S_{\infty}
\end{aligned}
$$

Equations (13) and (14) are boundary conditions on the surface of the structure, and the far-field radiation boundary condition, respectively.

\section{Wave forces}

The wave forces acting on a body can be determined by carried out appropriate integration of the pressure over the body surface. In the present application, the pressure in the fluid may be determined by the Bernoulli equation :

$$
p=-\rho\left[\frac{\partial \Phi}{\partial t}+\frac{1}{2}(\nabla \Phi \cdot \nabla \Phi)+g z\right]
$$

where $\rho$ is the fluid density, and $t$ denotes time. Substituting equation (5) into equation (15), and without considering the hydrostatic pressure term $\rho g z$, one can obtain a dynamic pressure equation:

$$
p=-\rho\left[\frac{\partial \phi_{w}}{\partial t}+\nabla \phi_{u} \cdot \nabla \phi_{w}+\frac{1}{2}\left(\left|\nabla \phi_{u}\right|^{2}+\left|\nabla \phi_{w}\right|^{2}\right]\right.
$$

Considering the case of small amplitude wave motion and small current velocity in the wave-current coexisting field, equation (16) can be rewritten into a first-order dynamic pressure equation expressed as

$$
p=-\rho\left[\frac{\partial \phi_{w}}{\partial t}+\nabla \phi_{u} \cdot \nabla \phi_{w}\right]
$$

It should be noted that the term $\nabla \phi_{u} \cdot \nabla \phi_{w}$ is of first order in wave amplitude, and accounts for the interaction between waves and current. Substituting equation (7) into equation (17), the first-order dynamic pressure equation is rewritten as:

$$
p=\frac{\rho g A}{\sigma}\left[\omega f+i\left(\nabla \phi_{u} \cdot \nabla f\right)\right] \frac{\cosh k(z+h)}{\cosh k h} e^{-i \omega t}
$$

The first-order wave forces acting on the body under the effect of a current can be determined by the integration of the first-order dynamic pressure equation over the surface of the object and the water depth. i.e.

$$
\left.\begin{array}{l}
F_{x}=\int_{-h}^{0} \int_{S_{1}} p d y d z \\
F_{y}=\int_{-h}^{0} \int_{S_{1}} p d x d z
\end{array}\right\}
$$

where $F_{x}, F_{y}$ represent, respectively, the first-order force components in the $x$ and $y$ directions.

\section{NUMERICAL PROCEDURE}

\section{Calculation of current velocity}

Consider the case of a flow past a two-dimensional body lying in the $x y$-plane. The object is assumed to be immersed in a uniform current which is inclined at an angle $\beta$ to the $x$ axis (Fig. 2). Applying the surface 
vorticity method (Lewis, 1991), one can represent this flow by a distributed vorticity sheet clothing the whole body but with initially unknown strength. Making use of the Biot-Savart law and boundary condition on the surface at $m$, a boundary integral equation can be obtained.

$$
\begin{aligned}
& \oint \gamma\left(s_{n}\right) K\left(s_{m}, s_{n}\right) d s_{n}-\frac{1}{2} \gamma\left(s_{m}\right) \\
& =-U\left(\frac{d x_{m}}{d s_{m}} \cos \beta+\frac{d y_{m}}{d s_{m}} \sin \beta\right)
\end{aligned}
$$

where the last term is the component of $U$ parallel to the body surface. $K\left(s_{m}, s_{n}\right)$ is a coupling coefficient whose value is that of the velocity at parallel to the body surface, induced by a unit vorticity located at $s_{n}$, namely

$K\left(s_{m}, s_{n}\right)=\frac{1}{2 \pi}\left\{\frac{-\left(x_{m}-x_{n}\right)\left(d y_{m} / d s_{m}\right)+\left(y_{m}-y_{n}\right)\left(d x_{m} / d s_{m}\right)}{\left(x_{m}-x_{n}\right)^{2}+\left(y_{m}-y_{n}\right)^{2}}\right\}$

Equation (20) is to be satisfied at all points on the body surface. A practical approach to approximate this would be to divide the body surface into $N$ discrete elements $\Delta s_{n}$, and pivotal points are selected at the midpoints of the elements (Fig. 3), whereupon, equation (20) may be expressed as a linear equation of the form:

$$
\sum_{n=1}^{N} \gamma\left(s_{n}\right) K(m, n) \Delta s_{n}=-U\left\{\frac{d x_{m}}{d s_{m}} \cos \beta+\frac{d y_{m}}{d s_{m}} \sin \beta\right\}
$$

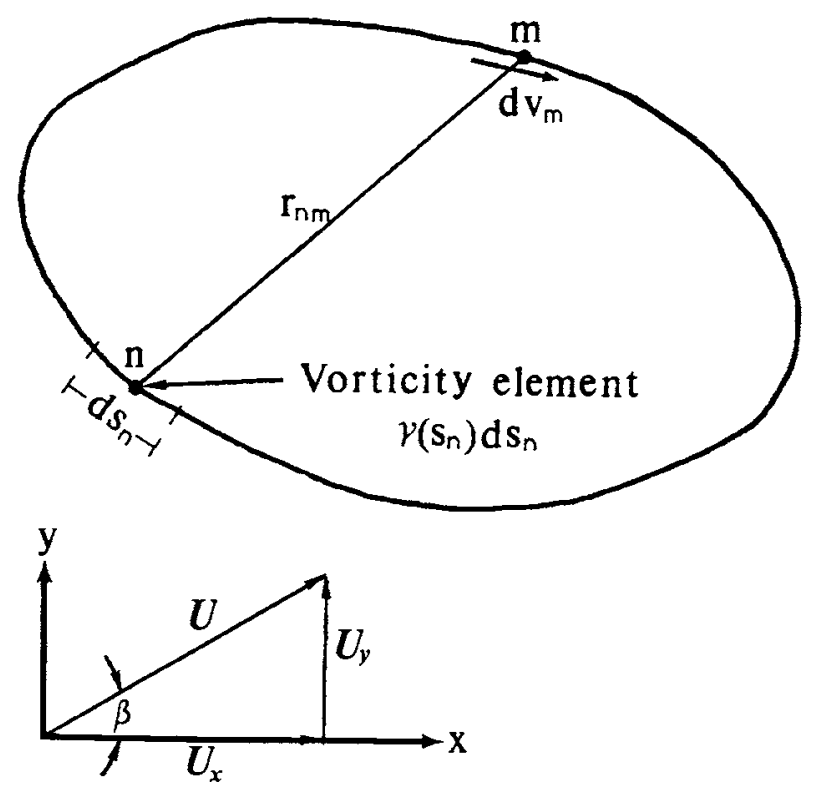

Fig. 2. Surface vorticity model for potential flow past a two-dimensional body.
Here, for simplicity, the $\gamma\left(s_{m}\right) / 2$ term on equation (20) has been absorbed into coupling coefficient $K(m, n)$, thus

$$
\begin{aligned}
K(m, n) & =K\left(s_{m}, s_{m}\right)-\frac{1}{2} ; n=m \\
& =K\left(s_{m}, s_{n}\right) \quad ; n \neq m
\end{aligned}
$$

Lewis (1991) showed that the coupling coefficient $K(m$, $n$ ) acting upon itself is given by

$$
K(m, m)=\Delta \theta_{m} / 4 \pi
$$

where $\Delta \theta_{m}$ is the angle subtended by the curved element $\Delta s_{m}$ (Fig. 3), and may be approximated by half the change of the slope between adjacent elements, namely

$$
\Delta \theta_{m}=\frac{1}{2}\left(\frac{d y_{m-1}}{d x_{m-1}}-\frac{d y_{m+1}}{d x_{m+1}}\right)
$$

A suitable discretization is achieved such that equation (22) must be written for the pivotal point of each element, resulting in a set of $N$ equations for $N$ unknown values of surface vorticity, $\chi(1), \gamma(2), \ldots, \gamma(N)$ Equation (22) then can be written in the matrix form:

$$
\left[\begin{array}{cccc}
K_{11} & \cdots & \cdots & K_{1 N} \\
K_{21} & \cdots & \cdots & K_{2 N} \\
\vdots & \vdots & \vdots & \vdots \\
K_{N 1} & \cdots & \cdots & K_{N N}
\end{array}\right]\left[\begin{array}{c}
\gamma\left(s_{1}\right) \\
\gamma\left(s_{2}\right) \\
\vdots \\
\gamma\left(s_{N}\right)
\end{array}\right]=\left[\begin{array}{c}
r h s_{1} \\
r h s_{2} \\
\vdots \\
r h s_{N}
\end{array}\right]
$$

with simplified notation $K_{m n}=K\left(s_{m}, s_{n}\right)$ and the right hand sides given by

$$
r h s_{m}=-U\left[\frac{d x_{m}}{d s_{m}} \cos \beta+\frac{d y_{m}}{d s_{m}} \sin \beta\right]
$$

Solution of the above $N$ linear equations then yield directly the value of surface vorticity $\gamma\left(s_{m}\right)$. The current velocity close to the body surface $\left(\nabla \phi_{u}\right)_{m}$ is now immediately known, being equal to the surface vorticity $\gamma\left(s_{m}\right)$ (Lewis, 1991).

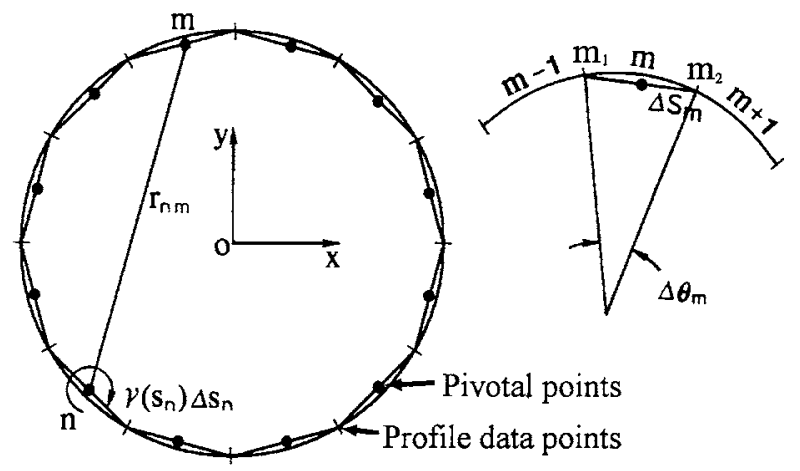

Fig. 3. Boundary element geometry. 


\section{Calculation of wave potential function}

Application of Green's second identity, and with the boundary condition on (equation (14)) to equation (12) leads to the following boundary integral equation :

$$
\begin{aligned}
& C_{i} f_{i}^{s}=\int_{S_{1}}\left(f^{s} \frac{\partial f^{*}}{\partial n}-f^{*} \frac{\partial f^{s}}{\partial n}\right) d s \\
& C_{i}= \begin{cases}1 & \text { in the analytical domain } D_{1} \\
\frac{1}{2} & \text { on the boundary } S_{1}\end{cases}
\end{aligned}
$$

where $\partial / \partial n$ is the normal derivative, directed outward from the fluid region at the structure surface. $f^{*}$ is the fundamental solution of the Helmholtz equation. Expressing the fundamental solution in terms of the Hankel function of the first kind of zero order, one has

$$
f^{*}=-\frac{i}{4} H_{0}^{(1)}(k r)
$$

where $r$ is the distance from the source point to the point under consideration. For the discretization of equation (27), constant elements on the boundary are used. Equation (28) can then be approximated and rewritten as

$$
\sum_{j=1}^{N} f_{j}^{s} \int_{s_{j}} \frac{\partial f^{*}}{\partial n} d s-C_{i} f_{i}^{s}=\sum_{j=1}^{N} \frac{\partial f_{j}^{*}}{\partial n} \int_{s_{j}} f^{*} d s
$$

This equation is to be satisfied at all points of the surface $S_{1}$. The resulting simultaneous equations written in matrix form can be expressed as

$$
\left[H_{i j}\right]\left[F_{j}\right]=\left[G_{i j}\right]\left[F_{j}^{*}\right]
$$

where

$$
\begin{aligned}
& H_{i j}=\int_{s_{j}} \frac{\partial}{\partial n}\left(-\frac{i}{4} H_{0}^{(1)}(k r)\right) d s \\
& G_{i j}=\int_{s_{j}}\left(-\frac{i}{4} H_{0}^{(1)}(k r)\right) d s \\
& F_{j}^{*}=\frac{\partial f_{j}^{s}}{\partial n}=-\frac{\partial f_{j}^{i}}{\partial n}
\end{aligned}
$$

From equation (31), the unknown quantities of the scattered wave potential function $\left[F_{j}\right]$ on boundary $S_{1}$ are solved by matrix inversion. Then the surface wave potential function $f=f^{i}+f^{s}$ is obtained.

\section{RESULTS AND DISCUSSION}

To examine and illustrate the present method, the special case of a large circular cylinder with radius a in constant water depth $(h)$ is considered. The incident waves are progressive in the positive $\mathrm{x}$ direction. For numerical computation, the ratio of water depth to the radius of the cylinder $h / a=1.0$, the Froude number $F_{r}=$ $U / \sqrt{g a}=0.05,0.10$, and different angles $\left(\theta=0^{\circ}, 45^{\circ}\right.$, $90^{\circ}, 135^{\circ}, 180^{\circ}$ ) between waves and current are chosen respectively. The wave number $k$ of a linear wave interacting with the current $U$ is obtained from the linear dispersion relation (equation (8)) with the value of $\omega$ $\left(\omega^{2}=g k^{\prime} \tanh k^{\prime} h\right.$, where $k^{\prime}$ is the zero-current wave number) (Thomas, 1981). With the value of $k a$, the first-order wave forces can be obtained from equation (19). Plotting them against $k a$, the variation of wave forces under the effect of a current can be seen clearly. For a large structure discussed in this study, the value of $2 a / L$ ( $L$ is the incident waves length) must be large than 0.2 (Brebbia,1979). Therefore, the region of $k a \leq 0.2 \pi$ can be out of consideration.

To verify the validity of this numerical model, wave forces on the cylinder without current effect (i.e. $F_{r}=0$ ) were calculated firstly. Figure 4 shows the calculated results together with the analytical solutions of MacCamy and Fuchs (1954). The agreement is rather satisfactory. A comparison is also made of the present numerical results for $F_{r}=0.10$ with those of Matsui et al. (1991) in figure 5. It indicates that the present results are in good agreement with those of Matsui et al. (1991) except for $k a=1.5 \sim 2.0$.

Variation of wave forces under the effects of following and opposing current with parameter $k a$ is presented in figure 6. It demonstrates that wave forces increase with increasing value of Froude number in the small wave number region $(k a<1.0)$, but decrease with increasing value of Froude number in the large wave number region $(k a>1.0)$. Wave forces are larger than

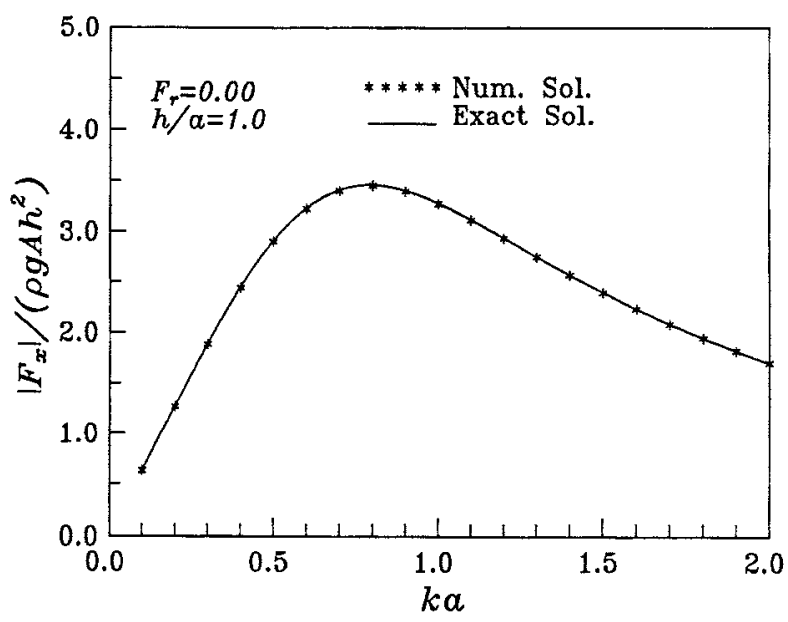

Fig. 4. Comparison of wave forces in absence of current between the numerical and exact solution. 


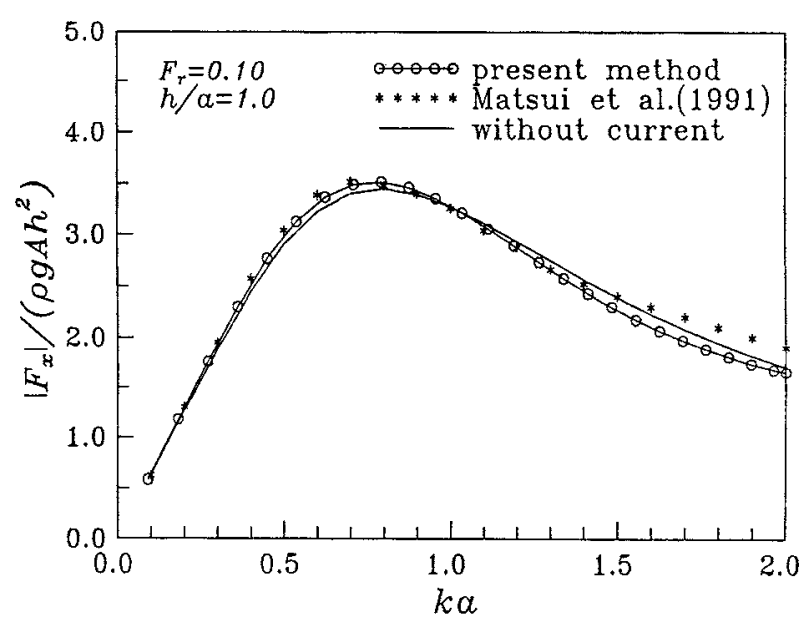

Fig. 5. Comparison of present results with those of Matsui et al. (1991) for $F_{r}=0.10$.

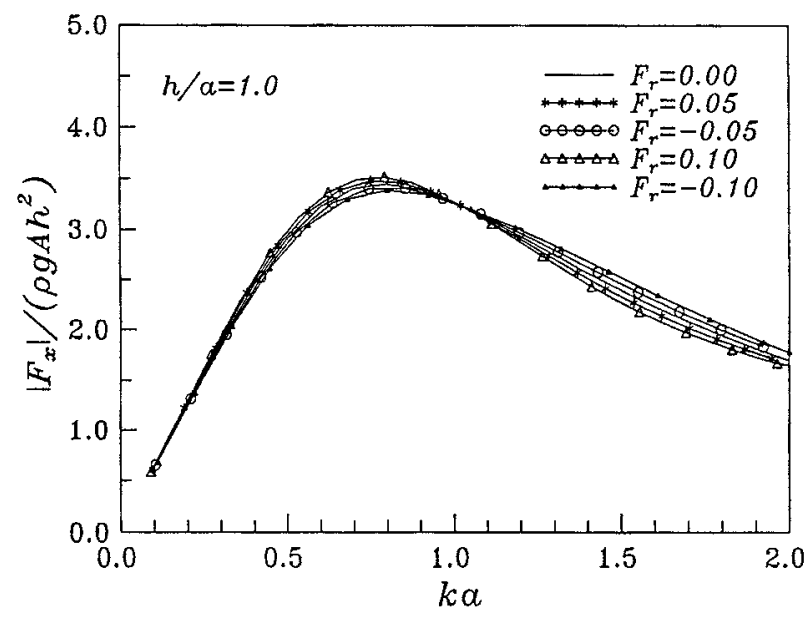

Fig. 6. Variation of wave forces with $k a$ under the effects of both following and opposing current.

that of no current present in the small wave number region for $F_{r}>0$ (i.e. under the effect of a following current), but smaller for Froude number $F_{r}<0$ (i.e. under the effect of an opposing current). An opposite trend can be observed in the large wave number region. This phenomenon can be due to the fact that the curve of the wave forces with no current present has a positive slope in the small wave number region, but has a negative slope in the large wave number region. For the reason of increasing wave length under the effect of a following current, i.e. the value of $k a$ is smaller than the relative diffraction parameter $k^{\prime} a$ of zero-current, so that the wave forces larger than that of current-free case in the small wave number region, but smaller in the large wave number region. The opposite trend is true for the case of an opposing current.

When the angles $(\theta)$ between waves and current are $45^{\circ}$ and $135^{\circ}$, waves will be refracted due to the influence of current. Therefore, the wave forces acting on the cylinder under the effect of a current have force components in the $y$-direction, besides in the $x$-direction. Figures 7 and 8 show the relationship between wave forces component in the $x$-direction and the diffraction parameter $\mathrm{ka}$. From these figures, it can be seen that, (a) with waves propagating on a favorable current $(\theta<$ $90^{\circ}$ ), wave forces in the $x$-direction become smaller compare to that of no current present in the large wave number region, and also decrease as the value of $F_{r}$ increases, (b) with waves propagating on an adverse current $\left(\theta>90^{\circ}\right)$, an opposite trend is found. Figure 9 demonstrates that wave force components in the $y$ direction increases as the value of $F_{r}$ increases. It means that the wave force components in the $y$-direction increases with increasing velocity of current.

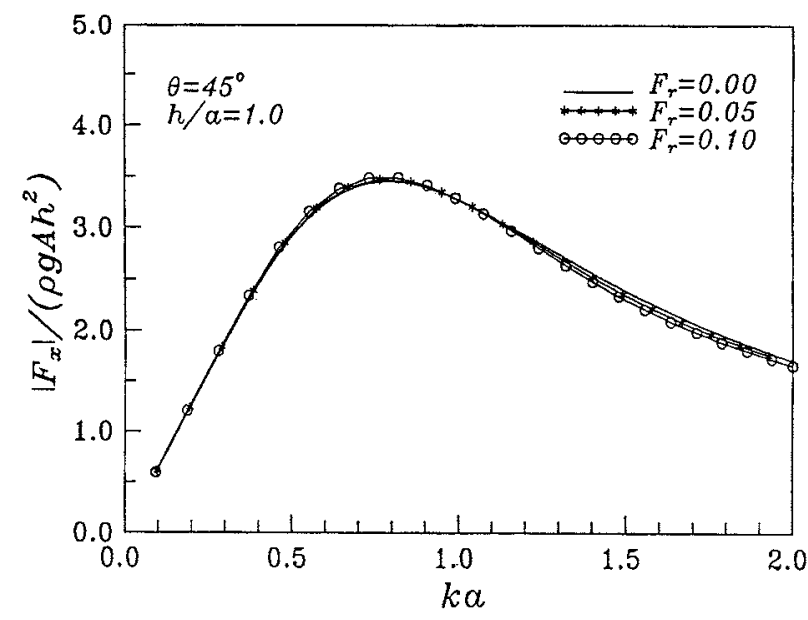

Fig. 7. Variation of wave forces in the $x$-direction with $k a$ for $\theta=45^{\circ}$ and different Froude numbers.

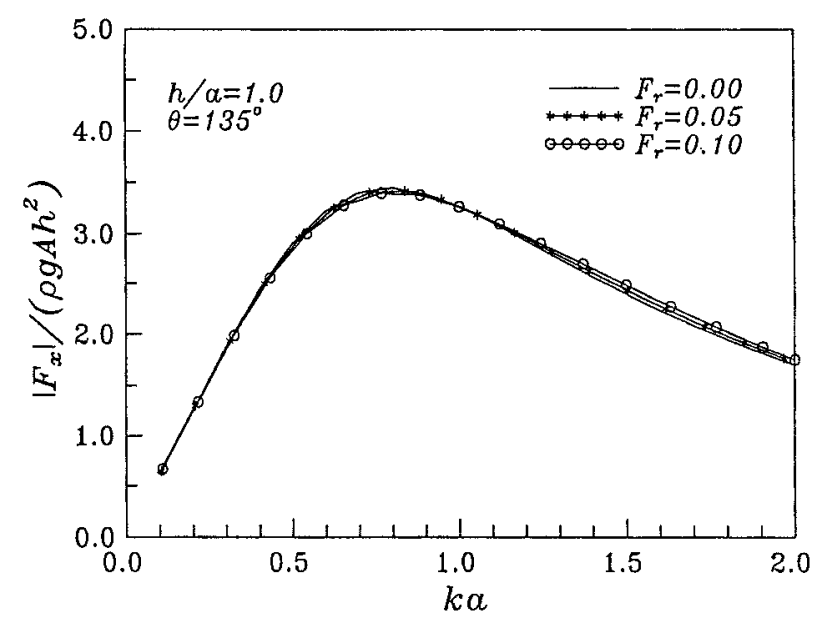

Fig. 8. Variation of wave forces in the $x$-direction with $k a$ for $\theta=135^{\circ}$ and different Froude numbers. 


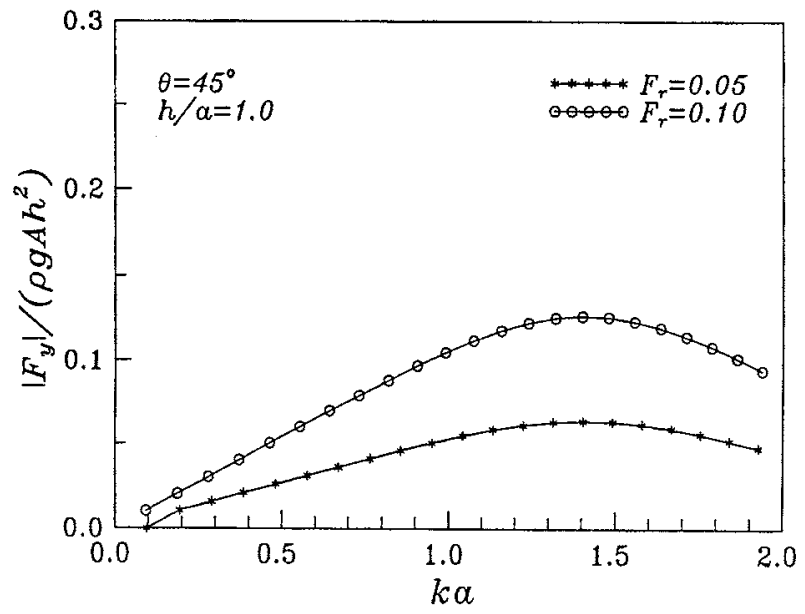

Fig. 9. Variation of wave forces in the $y$-direction with $k a$ for $\theta=45^{\circ}$ and different Froude numbers.

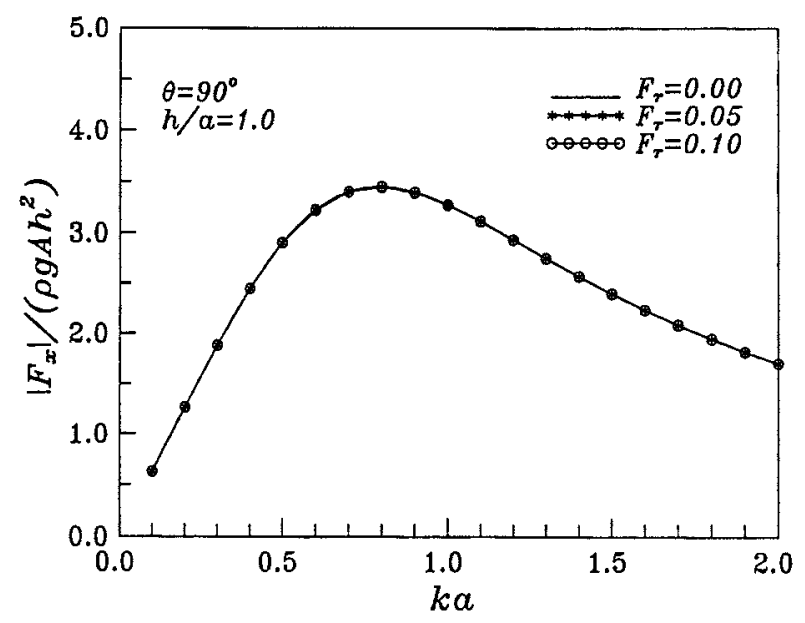

Fig. 10. Variation of wave forces in the $x$-direction with $k a$ for $\theta=90^{\circ}$ and different Froude numbers.

When the angle between waves and current is equal to $90^{\circ}$, the velocity of current has no component in the direction of the incident wave, so that the wave length will not be affected by current. Therefore, no matter what the value of $F_{r}$ is, the wave forces in the $x$ direction are the same as no current present (Fig. 10). Nevertheless, the wave force components in the $y$ direction are still affected by the existence of a current, and increase as the velocity of current increases (Fig. 11).

Figures 12 and 13 show the plots of wave forces in the $x$ and $y$-directions respectively, for different angles between waves and current, but with the same value of $F_{r}$ (i.e. the same current magnitude). Figure 12 reveals that the wave forces in the $x$-direction decrease with increasing angle between waves and current in the small

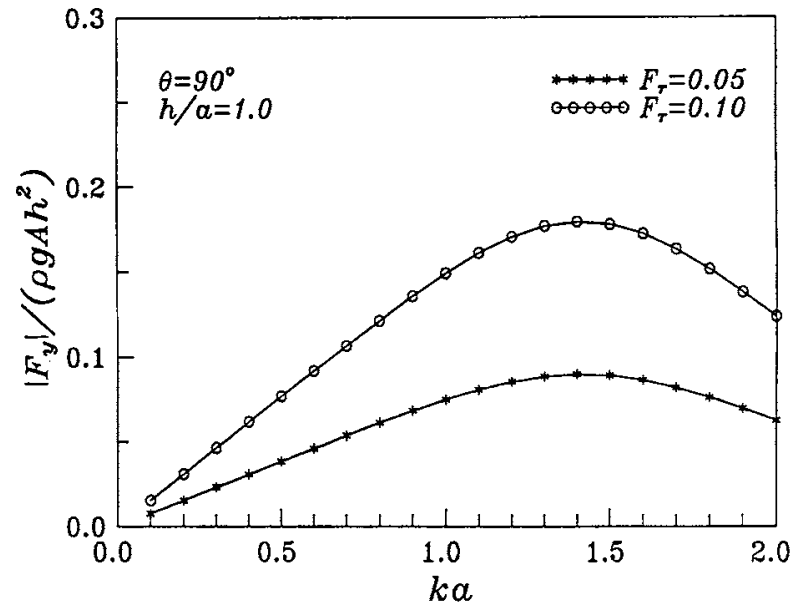

Fig. 11. Variation of wave forces in the $y$-direction with $k a$ for $\theta=90^{\circ}$ and different Froude numbers.

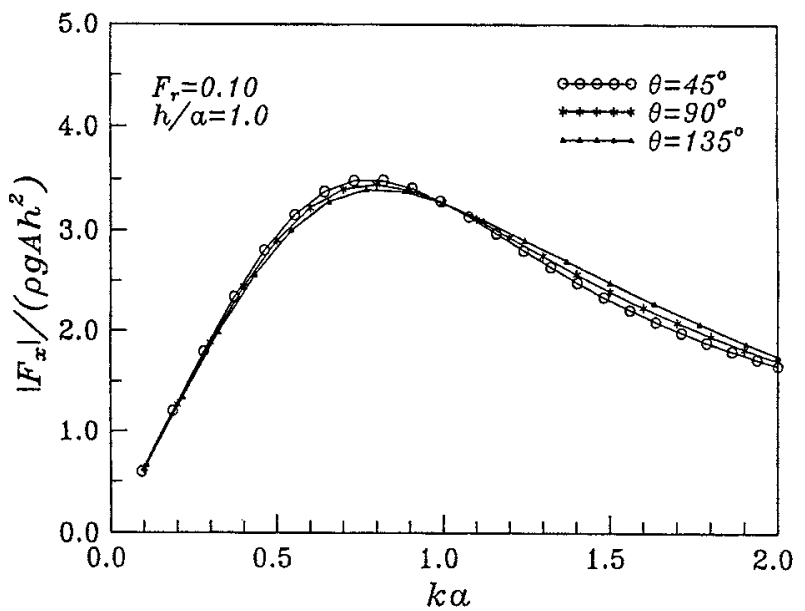

Fig. 12. Variation of wave forces in the $x$-direction with $k a$ for $F_{r}=0.10$ and different angles between waves and current.

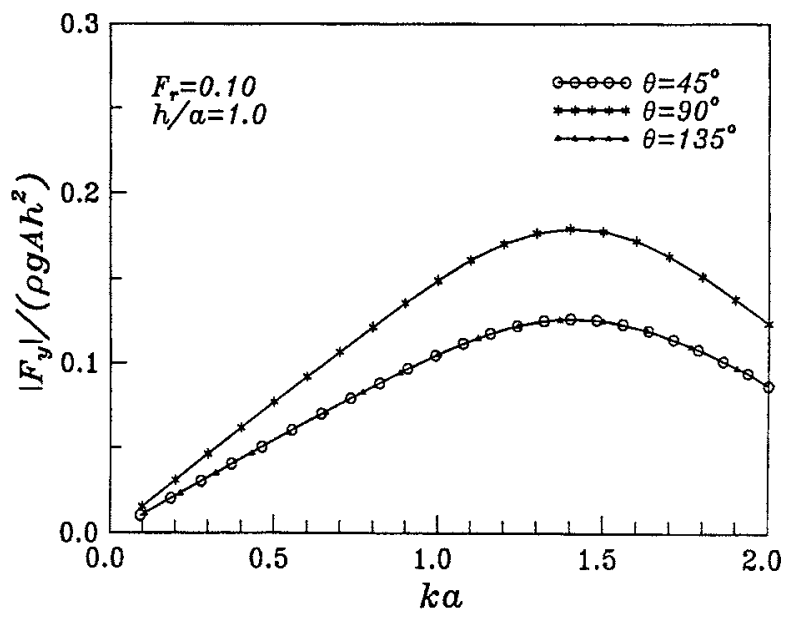

Fig. 13. Variation of wave forces in the $y$-direction with $k a$ for $F_{r}=0.10$ and different angles between waves and current. 
wave number region, but increase as the angle $(\theta)$ increases in the large wave number region. This is the fact that waves travel with current for $\theta<90^{\circ}$, whereas, it travels against the current for $\theta>90^{\circ}$. It can be therefore concluded that, the wave forces for the case of a following current is smaller than that without current in the large wave number region, but with an opposing current, a completely opposite trend can be detected. In Figure 13, it is found that the wave forces in the $y$ direction have a maximum value for $\theta=90^{\circ}$, and have the same value for $\theta=45^{\circ}$ and $\theta=135^{\circ}$. The reason for this is because that the velocity component of current in the y-direction has a maximum value when $\theta=90^{\circ}$, and has the same value for $\theta=45^{\circ}$ and $\theta=135^{\circ}$.

\section{CONCLUSIONS}

In this study, the surface vorticity method and boundary element method are combined to investigate the first-order wave forces on a large structure in the presence of a current. For the validity of this numerical model, comparison of the present results with the analytical solutions of MacCamy and Fuchs (1954) for zero-current, and with those of Matsui et al. (1991) for $F_{r}=0.10$ are made. The agreement is satisfactory. The numerical model proposed here has its adaptability to the problem of waves, current and a large structure interactions.

The following conclusions can be drawn from the numerical results :

1. Wave forces on a large body are larger than that of no current present in small wave number region for the incident waves travel with current, but smaller for the incident waves travel against current, and also increase with increasing value of Froude number. An opposite trend can be observed in the large wave number region.

2. When the intersection angle between waves and current is not equal to $0^{\circ}$ or $180^{\circ}$, it exists wave forces component in the $y$-direction. The wave forces increase as the velocity of current increases.

3. When the angle between waves and current is equal to $90^{\circ}$, the wave length will not be affected by current, the wave forces component on the $x$-direction are the same as that with no current present, nevertheless the wave forces component in the $y$-direction are still affected by the existence of a current, and increase as increasing current magnitude.

4. For a fixed current velocity (the value of Froude number is constant), but with different angles between waves and current, the wave forces in the $x$-direction increases as the angle increases in the large wave number region. An opposite trend can be observed in the small wave number region. Whereas the wave forces in the $y$-direction increase as the angle increases until the angle is equal to $90^{\circ}$, then decrease while the angle still increases. It means that the wave forces have a maximum value for $\theta=90^{\circ}$, and have the same value for the angles of inflow are symmetric to the $y$-direction (for example $\theta=45^{\circ}$ and $\left.\theta=135^{\circ}\right)$.

\section{REFERENCES}

1. Brebbia, C.A. and Walker, S., "Dynamic Analysis of Offshore structures," Newnes-Butterworths, London, pp. 129-130 (1979).

2. Isaacson, M. and Cheung, K.F., "Time-Domain Solution for Wave-Current Interactions with a Two-Dimensional Body," Applied Ocean Research, Vol.15, No. 1, pp. 3952 (1993).

3. Iwagaki, Y. and Asano, T., "Hydrodynamic Forces on a Circular Cylinder Combined Wave and Current Loading," Proc. 19th Int. Conf. on Coastal Eng., pp. 2857-2874 (1984).

4. Kirby, J.T., "A Note on Linear Surface Wave-Current Interaction over Slowly Varying Topography," $J$. Geophys. Res., Vol. 89, No. C1, pp. 745-747 (1984).

5. Lewis, R.I., Vortex Element Methods for Fluid Dynamic Analysis of Engineering Systems, Cambridge University Press, Cambridge, pp. 3-43 (1991).

6. Li, Y.C. and Zhang, C.R., "Forces on Cylinder in Coexisting Field of Regular Waves and Currents," China Ocean Engineering, Vol. 4, No. 1, pp. 43-54 (1990).

7. Li, Y.C., Wang, F.L., and Kang, H.G., "Wave-Current Forces on Slender Circular Cylinders," China Ocean Engineering, Vol. 5, No. 3, pp. 287-310 (1991).

8. Lin, M.C., Hsiao, S.S. and Ho, T.Y., "Combined Effects of Wave Diffraction-Refraction and Currents," Proc. 12th Conf. on Ocean Engineering in Taiwan, pp. 221235 (1990). (in Chinese)

9. Lin, M.C. and Hsu, Y.C., "Finite/Boundary Element Aanalysis of Combined Wave Refraction-Diffraction and Currents," 10th Ocean Engineering Symposium, The Society of Naval Architects of Japan, pp. 125-131 (1991).

10. Lin, M.C. and Hsiao, S.S. "Boundary Element Analysis of Wave-Current Interaction around a Large Structure," Engineering Analysis with Boundary Elements, Vol. 14, No. 4, pp. 325-334 (1994).

11. Lin, M.C., Hsiao, S.S. and Hsu, Y.C., "Wave RefractionDiffraction in the Presence of a Current," China Ocean Engineering, Vol. 8, No. 3, pp. 307-320 (1994).

12. Lin, M.C. and Hsiao, S.S., "Experimental Study on Wave-Current Interactions around a Large-Scale Cylinder," Coastal Engineering in Japan, Vol. 38, No. 1, pp. 41-61 (1995).

13. MacCamy, R.C. and Fuchs, R.A., "Wave Forces on 
Piles: a Diffraction Theory," Tech. Mem. No. 69, U.S Army Corps of Engineers, Beach Erosion Board, Washington D.C. (1954).

14. Matsui, T., Sano, K., and Lee, S. Y., "Hydrodynamic Forces on a Vertical Cylinder in Current and Waves," $J$. The Society of Naval Architects of Japan, Vol. 170, pp. 277-287 (1991). (in Japanese)

15. Thomas, G.P., "Wave-Current Interactions: An Experimental and Numerical Study. Part 1. Linear Waves," J. Fluid Mech., Vol. 110, pp. 457-474 (1981).

16. You, X.Y. and Tao, J.H., "Nonlinear Wave Forces on Large Scale Cylinders under the Effects of Current," J. Tianjin University, Vol. 2, pp. 32-37 (1992). (in Chinese)

17. Zhao, R. and Faltinsen, O.M., "Interaction between Waves and Current on a Two-Dimensional Body in the Free Surface," Applied Ocean Research, Vol. 10, No. 2, pp. 87-99 (1988).

\section{水流存在時作用於大型結構物之波 力解析}

蕭 松 山* 林 銘 崇**

*國立台灣海洋大學河海工程學系

**國立台灣大學造船及海洋工程學系

\section{摘 要}

本文提出一數值模式, 計算波流場中作用於大 型結構物之波力。模式中將波流共存場中之速度勢表 示爲定常水流速度勢及非定常波浪速度勢之組合。由 於實際上在結構物周邊水流速度將受結構物存在影響 而有所變化, 因此水流速度勢應分爲稳定均匀流速度 勢及水流受結構物影響之擾動速度势。但當結構物斷 面爲任意形狀時, 水流受結構物影響之擾動速度势求 解不易, 本文則應用表面漩渦法(surface vorticity method), 以數值方法直接計算求得水流受結構物影 響後之速度變化, 而不求解水流受結構物影響之擾動 速度勢。同時考虑非定常波浪速度勢爲受水流及結構 物影響之波浪速度勢, 應用繞射理論將波浪速度勢分 爲入射波及散射波速度勢, 其中入射波速度勢係受水 流影響後之速度勢爲已知值, 再利用邊界元素法數值 計算波浪受結構物影響後之散射波速度勢, 因而結構 物周邊之波浪速度勢即可獲得。最後將計算得到之結 構物周邊波浪速度勢及水流受結構物影響後之速度變 化, 代入第一階壓力方程式中, 則作用於結構物周邊 之波力即可求得。本文以大型圆柱爲例, 計算不同之 水流速度及波流交會角度時, 作用於大型圆柱之波 力, 計算結果與松井徹哉等(1991)之計算例比較, 二 者之結果尚稱吻合, 顯示本文模式適用於波、流與結 構物交互作用問題。

關鍵詞：波力、大型結構物、波流共存場。 